Artículo

\title{
Respuesta de genotipos de avena a la infección por Bipolaris victoriae y Bipolaris sorokiniana
}

\author{
Santos Gerardo Leyva-Mir ${ }^{1}$ \\ Héctor Eduardo Villaseñor-Mir² \\ Juan Manuel Tovar-Pedraza ${ }^{3}$ \\ Elizabeth García-León ${ }^{4 \S}$
}

${ }^{1}$ Departamento de Parasitología Agrícola-Universidad Autónoma Chapingo, Carretera México-Texcoco km 38.5, Chapingo, Texcoco, Estado de México, México. CP. 56230. Tel. 01(595) 9521500, ext. 6304. (1santos@correo.chapingo.mx). ${ }^{2}$ Campo Experimental Valle de México-INIFAP. Carretera Los ReyesTexcoco km 13.5, Coatlinchán, Texcoco, Estado de México, México. CP. 56230. Tel. 01(595) 9212715, ext. 161. (villasenor.hector@inifap.gob.mx). ${ }^{3}$ Centro de Investigación en Alimentación y DesarrolloUnidad Culiacán. Carretera Culiacán-El dorado km 5.5, Campo El Diez, Culiacán, Sinaloa, México. CP. 80110. (jmtovarp91@ gmail.com). ${ }^{4}$ Campo Experimental Valle del Fuerte-INIFAP. Carretera Internacional Mexico-Nogales km 1609, Juan José Ríos, Guasave, Sinaloa, México. CP. 81110.

${ }^{\S}$ Autor para correspondencia: egarcialeon55@gmail.com.

\section{Resumen}

El cultivo de avena (Avena sativa L.) es afectado por un amplio rango de enfermedades foliares causadas por hongos patógenos, entre estos los más importantes son las inducidas por Bipolaris spp., los cuales causan severos tizones foliares, principalmente en la zona de los Valles Altos de México. El objetivo de este estudio fue identificar molecularmente los dos aislamientos asociados al tizon foliar en avena y determinar la respuesta de 30 variedades comerciales de avena de la Colección Nacional a la infección por B. victoriae y B. sorokiniana bajo condiciones de invernadero. Un aislado de $B$. victoriae y un aislado de $B$. sorokiniana, se incrementaron para inocular plantas de 30 variedades de avena mediante la aspersión de una suspensión de esporas al follaje. El diseño experimental empleado fue en bloques al azar para cada uno de los aislados, se evaluaron 30 tratamientos que consistieron en las variedades analizadas, cada tratamiento constó de 20 plantas con cuatro repeticiones. Se midió el daño foliar como variable de repuesta para determinar la severidad a la enfermedad. Se observó que las variedades AB-177, Cuauhtémoc, Gema, Texas, Nodaway y Pampas se comportaron como las más susceptibles a B. sorokiniana, mientras que, las variedades Teporaca y Nuda mostraron ser moderadamente resistentes a éste patógeno. Para el caso de B. victoriae, se observó que las variedades Juchitepec y Ópalo fueron resistentes, entretanto, las variedades Gema, Bachiniva y Cevamex se comportaron como las más susceptibles a la infección.

Palabras clave: Avena sativa, resistencia, severidad, tizones.

Recibido: abril de 2019

Aceptado: julio de 2019 


\section{Introducción}

La avena (Avena sativa L.) es el séptimo cereal más cosechado a nivel mundial con 25 millones de toneladas en grano, posicionando a Rusia (4 millones de toneladas), Canadá (2.7 mt), Estados Unidos de América (2.5 mt), Polonia (1.5 mt), Australia (1.3 mt) y Finlandia (1.1 mt) como los principales países productores, (FAO, 2014; USDA, 2017; Consejo Internacional de Cereales, 2018).

En México, la producción de avena ha crecido en los últimos 20 años de aproximadamente 500 mil hectáreas a un millón de hectáreas, sembradas en $80 \%$ bajo condiciones de temporal y destinadas en $85 \%$ para la producción de forraje. Del total de superficie sembrada en 2015 para riego y temporal, cerca de 765 mil hectáreas (grano y forrajera). Los estados de Chihuahua, Coahuila, Durango y Zacatecas aportaron la mayor parte de la superficie sembrada con rendimientos por encima de las $20 \mathrm{t} \mathrm{ha}^{-1}$ para avena forrajera y $2 \mathrm{t} \mathrm{ha}^{-1}$ para avena grano (SIAP, 2016).

Asimismo, cerca de $80 \%$ de la producción nacional de avena se destina principalmente para el sector pecuario, ya sea para su consumo como forraje verde o henificado, en grano y en la elaboración de alimentos balanceados, mientras que, el resto de la producción se utiliza para diversos sectores entre ellos el alimenticio (Villaseñor-Mir et al., 2009).

El incremento de la superficie de siembra se debe a que en México se le considera como como cultivo alternativo en los Valles Altos y en la región semiárida del Norte Centro, particularmente cuando el inicio del período de lluvias se retrasa o se presentan bajas temperaturas que ponen en riesgo la siembra de los cultivos tradicionales de maíz y frijol (Villaseñor-Mir et al., 2003).

En México, la avena es la especie más utilizada para la reconversión productiva de las tierras de baja productividad donde la estación de crecimiento es corta, y el cambio climático requiere la siembra extensiva de especies rústicas, poco demandantes de agua y un ciclo biológico reducido. Asimismo, se requiere disponer de variedades aptas para la producción de forraje y grano con bondades agronómicas que sean resistentes o tolerantes a la ocurrencia de heladas tempranas y déficit hídrico intermitente y a fitopatológicas que permitan minimizar el efecto negativo de las enfermedades como la roya del tallo (Puccinia graminis f. sp. avenae), roya de la corona (Puccinia coronata f. sp. avenae) y el complejo de tizones foliares causado por Bipolaris spp.

Sin embargo, existen reportes de una amplia diversidad de especies de hongos causantes de enfermedades foliares tales como Colletotrichum graminicola, Curvularia hawaiiensis, Drechslera avenacea, Passalora graminis, Bipolaris victoriae y Bipolaris sorokiniana (VillaseñorMir et al., 2003; García-León et al., 2013; 2015). Dentro de los patógenos de mayor importancia en las zonas productoras de México destaca Bipolaris spp. agente causal de tizones foliares, debido a la amplia incidencia y distribución de estos patógenos en los Valles Altos de México (GarcíaLeón et al., 2013).

Se ha encontrado que el complejo de Bipolaris spp. es más común ambientes lluviosos (>700 mm) de las partes altas de los Valles de Altos de México, y es menos frecuente en ambientes medio lluviosos (500-600 mm), ya que estas enfermedades requieren de temperaturas frescas y alta humedad relativa (Villaseñor-Mir et al., 1998). Los avances tecnológicos, principalmente en el uso de fungicidas no han contribuido al control de estas enfermedades. Sin embargo, el uso de 
variedades tolerantes o resistentes a este complejo de patógenos foliares es el método de control más adecuado desde el punto de vista ambiental y ecológico (Leyva-Mir et al., 2014). Por lo anterior, el objetivo del presente trabajo fue determinar la respuesta de 30 variedades comerciales de avena a la infección por B. victoriae y B. sorokiniana bajo condiciones de invernadero.

\section{Materiales y métodos}

\section{Sitio de estudio}

El experimento se llevó a cabo en el laboratorio nacional de royas y otras enfermedades de trigo ubicado en el Campo Experimental Valle de México (LANAREC-CEVAMEX), perteneciente al Instituto Nacional de Investigaciones Forestales, Agrícolas y Pecuarias (INIFAP).

\section{Extracción de ADN, PCR y secuenciación}

Se tomó de 50 a 100 g de crecimiento micelial puro de 8 días en medio de cultivo PDA, el cual fue macerado con nitrógeno líquido. El macerado se colocó en un tubo de microcentrífuga de $1.5 \mathrm{~mL}$ y se le agregaron $500 \mu \mathrm{L}$ de buffer de extracción (Tris $0.1 \mathrm{M} \mathrm{pH} \mathrm{8,} \mathrm{EDTA} 10 \mathrm{mM}, 2 \%$ SDS, $0.2 \mathrm{mg}$ $\mathrm{mL}^{-1}$ de proteínas $\mathrm{K}$ ). Esto se mantuvo durante $10 \mathrm{~min}$ a $38^{\circ} \mathrm{C}$ en 'baño maría'. Después de este periodo se colocaron $30 \mu \mathrm{L}$ de CTAB $10 \%$ y $70 \mu \mathrm{L}$ de $\mathrm{NaCl} 5 \mathrm{M}$, y se mantuvo a $65{ }^{\circ} \mathrm{C}$ durante 10 min, se agregaron $100 \mu \mathrm{L}$ de acetato de potasio $5 \mathrm{M}$ y se incubó en hielo por $5 \mathrm{~min}$, luego se añadieron $700 \mu \mathrm{L}$ de cloroformo-alcohol isoamílico (24:1) y se centrifugo a 13000 x g durante $10 \mathrm{~min}$.

El sobrenadante se transfirió a un tubo de micro centrifuga de $1.5 \mathrm{~mL}$ nuevo y se agregaron 640 $\mu \mathrm{L}$ de isopropanol frío y $60 \mu \mathrm{L}$ de acetato de sodio $3 \mathrm{M}$ pH 5.8, esto se mezcló por inversión tres veces de manera suave y se incubo durante 5 min a $-20{ }^{\circ} \mathrm{C}$. Después, se centrifugó a 13000 x g durante $10 \mathrm{~min}$, el sobrenadante se desechó; se agregaron $500 \mu \mathrm{L}$ de etanol al $70 \%$ y se centrifugo a $13000 \mathrm{x}$ g durante $5 \mathrm{~min}$. El sobrenadante se extrajo y se dejó secar la pastilla para posteriormente re suspenderla en $100 \mu \mathrm{L}$ de agua destilada estéril libre de DNAasa. El ADN obtenido se verificó mediante una electroforesis en agarosa al 1\% usando TAE $1 \mathrm{X}$ como buffer de corrida a 90 volts. Los resultados fueron observados en un transiluminador Gel-Doc mod 2000 (Biorad $\left.{ }^{\circledR}\right)$.

La PCR se llevo a cabo en un termociclador Biorad ${ }^{\circledR}$ con una mezcla de reacción compuesta por buffer de PCR 1X, $2.5 \mathrm{mM} \mathrm{MgCl} 2,0.20 .4 \mathrm{mM}$ dNTP, $\mu \mathrm{M}$ de cada iniciador, $1 \mathrm{U}$ de Taq DNA polimerasa (Promega ${ }^{\circledR}$ ) y $100 \mathrm{ng}$ de ADN, completando un volumen final de $25 \mu \mathrm{L}$ con agua libre de nucleasas. El protocolo de PCR para los iniciadores ITS 5 y 4 consistió en la desnaturalización inicial de $95{ }^{\circ} \mathrm{C}$ durante $3 \mathrm{~min}, 35$ ciclos de $95-55-72{ }^{\circ} \mathrm{C}$ durante $30-30-60$ s respectivamente, extension final de $72{ }^{\circ} \mathrm{C}$ por $10 \mathrm{~min}$.

Los productos de PCR amplificados fueron verificados por electroforesis a 90 volts en un gel de agarosa al $1 \%$ con buffer de corrida TAE $1 \mathrm{X}$. El gel fue observado y analizado con el transiluminador Gel-Doc mod $2000\left(\right.$ Biorad $\left.^{\circledR}\right)$.

Para obtener la secuenciación de ADN fue necesario purificar los fragmentos amplificados por los iniciadores ITS 4 y 5, utilizando el protocolo de DNA clean y concentrato ${ }^{\mathrm{TM}-5}$. En un tubo de micro centrifuga de $1.5 \mathrm{~mL}$ se colocó el producto de PCR y se le agregaron 5 volúmenes de buffer DNA Binding y se mezcló por inversión. La mezcla se transfirió a una columna Zymo-Sping en un tubo de colección de $2 \mathrm{~mL}$ y se centrifugó durante 30 s a $8000 \mathrm{rpm}$, descartando el sobrenadante. 
Al resultado se le agregaron $200 \mu \mathrm{L}$ de buffer DNA Wash en la columna y se centrifugo a 8000 rpm durante $30 \mathrm{~s}$ y se desechó el sobrenadante, se repitió este paso. Después de adicionaron $60 \mu \mathrm{L}$ de buffer DNA Elution directamente en la columna y se incubo durante $1 \mathrm{~min}$, la columna se transfirió a tubo nuevo de $1.5 \mathrm{~mL}$ para micro centrifuga, para diluir el ADN se centrifugo durante $30 \mathrm{~s}$ (Zymo Research). El ADN purificado se envió a secuenciar a la empresa Macrogen ${ }^{\circledR}$ en Corea, para después compararlas con la base de datos del National Center for Biotechnology Information (NCBI) en el programa Basic Local Alignment Search Tool (Blast https://blast.ncbi.nlm.nih.gov/ Blast.cgi).

\section{Inóculo}

En este estudio se utilizaron los aislados de Bipolaris victoriae (número de acceso del GenBank EF452448) y Bipolaris sorokiniana (GenBank EF452447). Para favorecer la producción de conidios, los aislados se incrementaron en cajas Petri con medio de cultivo V8 a $25^{\circ} \mathrm{C}$ y se corroboraron sus características morfológicas por medio de montajes semipermanentes.

Las características morfológicas de los conidios de $B$. victoriae corresponden a: conidios de color café claro, delgados, ligeramente curvos, redondeados y estrechos hacia los extremos, con 4-11 septas, aunque generalmente de 8 y miden 40-120 x 12-19 $\mu \mathrm{m}$. Los conidióforos son solitarios o en grupos, rectos, de color café claro, miden hasta $250 \mu \mathrm{m}$ de largo y 6-10 $\mu \mathrm{m}$ de espesor.

Las características morfológicas de los conidios de $B$. sorokiniana corresponden a conidios de color negros ovales y de aspecto brillante ligeramente curvos y adelgazados hacia su punta, con 5-9 septas, los conidióforos son solitarios o en grupos, rectos, no ramificados aproximadamente de 40$120 \mu \mathrm{m}$ de largo X 18-28 $\mu \mathrm{m}$ de ancho. La descripción morfológica anterior coincide con lo mencionado por Leyva y Romero (1982).

\section{Variedades evaluadas}

Las variedades evaluadas en este estudio fueron: AB-177, Babícora, Bachiniva, Cevamex, Chihuahua, Cuauhtémoc, Cusihuiriachi, Diamante R-31, Gema, Guelatao, Huamantla, Juchitepec, Karma, Menonita, Nodaway, Nuda, Obsidiana, Ópalo, Pampas, Papigochi, Paramo, Perla, Putnam-61, Rarámuri, Saia (perteneciente a la especie Avena strigosa), Tarahumara, Teporaca, Texas, Tulancingo y Turquesa, cuales pertenecen a la Colección Nacional de variedades de avena del Instituto Nacional de Investigaciones Forestales, Agrícolas y Pecuarias (INIFAP), dichas variedades se seleccionaron en base a diversos parámetros y características de rendimiento, ciclo productivo, propósito (grano o forraje) y frecuencia de siembra en las regiones aveneras de México.

\section{Inoculación de variedades de avena con $\boldsymbol{B}$. victoriae y $\boldsymbol{B}$. sorokiniana}

Una vez incrementados los aislados fúngicos, se procedió a la inoculación de las plantas de las 30 variedades de avena. Para ello, se preparó una suspensión de conidios a una concentración de $1 \mathrm{x}$ $10^{6}$ esporas $\mathrm{mL}^{-1}$, adicionada con Tween 20 (Sigma ${ }^{\circledR}$, EE. UU) de cada uno de los aislamientos. Posteriormente, con las suspensiones de conidios de los aislados se asperjaron sobre las hojas de las plantas de avena de $30 \mathrm{~d}$ de edad con un atomizador manual. Las plantas se mantuvieron en una cámara de incubación con ambiente controlado durante $72 \mathrm{~h}$ a una humedad relativa $>95 \%$ para lo 
cual se usó un humidificador ultrasónico HU-820A (Samsung Electronic, Corea) y temperatura media de 19 a $21^{\circ} \mathrm{C}$ por $48 \mathrm{~h}$. Después se trasladaron al invernadero donde se mantuvieron hasta la aparición de síntomas a una temperatura que osciló de 21 a $30{ }^{\circ} \mathrm{C}$ por 10 días.

Las plantas inoculadas fueron distribuidas en un diseño de bloques al azar para cada uno de los aislados, se obtuvieron 30 tratamientos para cada aislamiento que consistieron las variedades a evaluar, cada tratamiento constó de 20 plantas con cuatro repeticiones, lo que dio un total de 80 plantas por cada tratamiento. La variable respuesta a evaluar fue la severidad de la enfermedad en cada variedad, la cual se determinó como el porcentaje de la superficie de la hoja que presentaba síntomas a los 10 días después de la inoculación. Se utilizó la escala de 8 niveles de severidad propuesta por Mehta (2014).

El experimento de evaluación de la severidad se realizó dos veces bajo condiciones de invernadero. Los datos obtenidos de la respuesta de los tratamientos se determinaron mediante un análisis de varianza y la comparación de medias se realizó mediante la prueba de Tukey $(p<0.05)$ con el programa SAS ${ }^{\circledR}$ Versión 9.1.

\section{Resultados y discusión}

En este estudio se utilizaron los aislados identificados molecularmente y depositados en el GenBank como Bipolaris victoriae (número de acceso EF452448) y Bipolaris sorokiniana (GenBank EF452447). Dichos aislados se encuentran depositados en la Colección de Hongos Fitopatógenos del Departamento de Parasitología Agrícola de la Universidad Autónoma Chapingo.

\section{Severidad de B. victoriae y B. sorokiniana}

Las evaluaciones de severidad se iniciaron a los diez días cuando se observaron síntomas de atizonamiento del área foliar además de clorosis generalizada y albinismo apical.

Los tratamientos presentaron diferencias significativas en el efecto de los tratamientos $(p=0.0001)$ (Cuadro 1), donde las variedades con mayor susceptibilidad a B. sorokiniana fueron AB-177, Cuauhtémoc, Gema, Texas, Nodaway y Pampa, mientras que, las variedades en las que se observó el menor porcentaje de severidad fueron Nuda y Teporaca (Figura 1).

Cuadro 1. Comparación de severidad de enfermedad causados por Bipolaris victoriae y $\boldsymbol{B}$. sorokiniana en variedades comerciales de avena en México.

\begin{tabular}{ccccc}
\hline Variedad & $\begin{array}{c}\text { Severidad } \\
\text { B. victoriae }\end{array}$ & $\begin{array}{c}\text { Respuesta a } \\
\text { B. victoriae }\end{array}$ & $\begin{array}{c}\text { Severidad } \\
\text { B. sorokiniana }\end{array}$ & $\begin{array}{c}\text { Respuesta a } B . \\
\text { sorokiniana }\end{array}$ \\
\hline AB-177 & $25 \mathrm{ABC}^{*}$ & $\mathrm{MS}$ & $80.7 \mathrm{~A}$ & $\mathrm{AS}$ \\
Babícora & $22.5 \mathrm{ABC}$ & $\mathrm{MS}$ & 50 DEFGHIJ & $\mathrm{S}$ \\
Bachiniva & $32.5 \mathrm{AB}$ & $\mathrm{S}$ & $34.1 \mathrm{GHIJK}$ & $\mathrm{MS}$ \\
Cevamex & $30 \mathrm{AB}$ & $\mathrm{S}$ & $59.1 \mathrm{ABCDEFG}$ & $\mathrm{S}$ \\
Chihuahua & $22.5 \mathrm{ABC}$ & $\mathrm{MS}$ & $59.2 \mathrm{ABCDEFG}$ & $\mathrm{S}$ \\
Cuauhtémoc & $25 \mathrm{ABC}$ & $\mathrm{MS}$ & $78.8 \mathrm{AB}$ & $\mathrm{AS}$ \\
Cusihuiriachi & $17.5 \mathrm{BC}$ & $\mathrm{MR}$ & $57.1 \mathrm{ABCDEFG}$ & $\mathrm{S}$ \\
Diamante R-31 & $17.5 \mathrm{BC}$ & $\mathrm{MR}$ & $59.7 \mathrm{ABCDEF}$ & $\mathrm{S}$ \\
\hline
\end{tabular}




\begin{tabular}{ccccc}
\hline Variedad & $\begin{array}{c}\text { Severidad } \\
\text { B. victoriae }\end{array}$ & $\begin{array}{c}\text { Respuesta a } \\
\text { B. victoriae }\end{array}$ & $\begin{array}{c}\text { Severidad } \\
\text { B. sorokiniana }\end{array}$ & $\begin{array}{c}\text { Respuesta a } B . \\
\text { sorokiniana }\end{array}$ \\
\hline Gema & $37.5 \mathrm{~A}$ & $\mathrm{~S}$ & $70.4 \mathrm{ABCD}$ & $\mathrm{AS}$ \\
Guelatao & $15 \mathrm{BC}$ & $\mathrm{MR}$ & $51.2 \mathrm{DEFGHIJ}$ & $\mathrm{S}$ \\
Huamantla & $17.5 \mathrm{BC}$ & $\mathrm{MR}$ & $30.5 \mathrm{HIJK}$ & $\mathrm{MS}$ \\
Juchitepec & $10 \mathrm{C}$ & $\mathrm{R}$ & $47.5 \mathrm{DEFGHIJK}$ & $\mathrm{S}$ \\
Karma & $25 \mathrm{ABC}$ & $\mathrm{MS}$ & $47.4 \mathrm{DEFGHIJK}$ & $\mathrm{S}$ \\
Menonita & $17.5 \mathrm{BC}$ & $\mathrm{MR}$ & $35.8 \mathrm{FGHIJ}$ & $\mathrm{MS}$ \\
Nodaway & $15 \mathrm{BC}$ & $\mathrm{MR}$ & $76.8 \mathrm{ABC}$ & $\mathrm{AS}$ \\
Nuda & $15 \mathrm{BC}$ & $\mathrm{MR}$ & $27.9 \mathrm{JK}$ & $\mathrm{MR}$ \\
Obsidiana & $25 \mathrm{ABC}$ & $\mathrm{MS}$ & $56.3 \mathrm{ABCDEFG}$ & $\mathrm{S}$ \\
Ópalo & $10 \mathrm{C}$ & $\mathrm{R}$ & $39.8 \mathrm{EFGHIJK}$ & $\mathrm{MS}$ \\
Pampas & $17.5 \mathrm{BC}$ & $\mathrm{MR}$ & $72.6 \mathrm{ABCD}$ & $\mathrm{AS}$ \\
Paramo & $17.5 \mathrm{BC}$ & $\mathrm{MR}$ & $62.2 \mathrm{ABCDE}$ & $\mathrm{AS}$ \\
Papigochi & $25 \mathrm{ABC}$ & $\mathrm{MS}$ & $59.3 \mathrm{ABCDEFG}$ & $\mathrm{S}$ \\
Putnam-61 & $22.5 \mathrm{ABC}$ & $\mathrm{MS}$ & $57.1 \mathrm{ABCDEFG}$ & $\mathrm{S}$ \\
Perla & $27.5 \mathrm{ABC}$ & $\mathrm{MS}$ & $54 \mathrm{BCDEFGHI}$ & $\mathrm{S}$ \\
Rarámuri & $30 \mathrm{AB}$ & $\mathrm{S}$ & $66.4 \mathrm{ABCD}$ & $\mathrm{AS}$ \\
Saia & $15 \mathrm{BC}$ & $\mathrm{MR}$ & $30.1 \mathrm{IJK}$ & $\mathrm{MS}$ \\
Tarahumara & $30 \mathrm{AB}$ & $\mathrm{S}$ & $53.3 \mathrm{CDEFGHI}$ & $\mathrm{S}$ \\
Teporaca & $25 \mathrm{ABC}$ & $\mathrm{MS}$ & $22.7 \mathrm{~K}$ & $\mathrm{MR}$ \\
Texas & $27.5 \mathrm{ABC}$ & $\mathrm{MS}$ & $71.5 \mathrm{ABCD}$ & $\mathrm{AS}$ \\
Tulancingo & $20 \mathrm{ABC}$ & $\mathrm{MR}$ & $61.1 \mathrm{ABCDE}$ & $\mathrm{AS}$ \\
Turquesa & $15 \mathrm{BC}$ & $\mathrm{MR}$ & $55.5 \mathrm{ABCDEFGH}$ & $\mathrm{S}$ \\
\hline
\end{tabular}

${ }^{*}=$ medias dentro de cada columna seguidas por la misma letra no difieren en la prueba de Tukey al $5 \%$ de probabilidad.

Para el caso de B. victoriae, las variedades más susceptibles fueron Gema, Bachiniva y Cevamex, entretanto, las variedades Juchitepec y Ópalo mostraron resistencia a este hongo fitopatógeno (Figura 2). Cabe destacar, que los rangos de severidad causados por cada especie de Bipolaris presentaron grandes diferencias, por lo que las categorías (resistente, moderadamente resistente, moderadamente susceptible y susceptible) se definieron con base en la severidad mínima y máxima para cada patógeno.

\section{Bipolaris victoriae}

$\mathrm{R}=$ resistente $(0-10 \%$ de severidad); $\mathrm{MR}=$ moderadamente resistente $(10.1-20 \%$ de severidad); $\mathrm{MS}=$ moderadamente susceptible $(20.1-30 \%$ de severidad); $\mathrm{S}=$ susceptible ( $>30 \%$ de severidad).

\section{Bipolaris sorokiniana}

$\mathrm{R}=$ resistente $(0-15 \%$ de severidad); $\mathrm{MR}=$ moderadamente resistente $(15.1-30 \%$ de severidad); $\mathrm{MS}=$ moderadamente susceptible $(30.1-45 \%$ de severidad); $\mathrm{S}=$ susceptible $(45.1-60 \%$ de severidad): $\mathrm{AS}=$ altamente susceptible $(>60 \%$ de severidad $)$. 


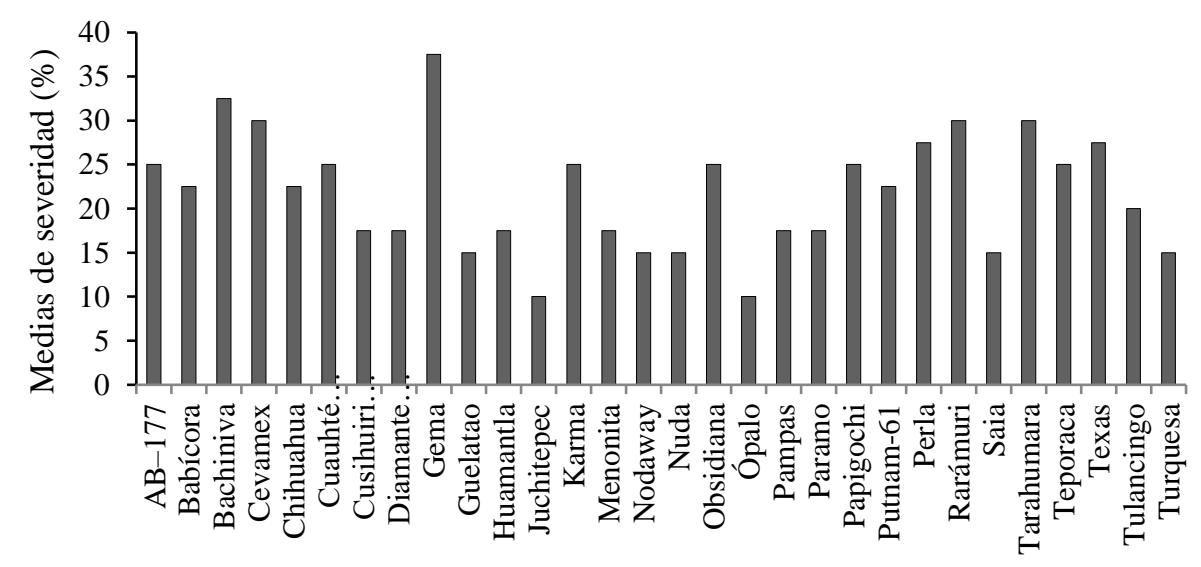

Figura 1. Respuesta grafica de la severidad (\%) causada por $\boldsymbol{B}$. victoriae en 30 variedades de avena.

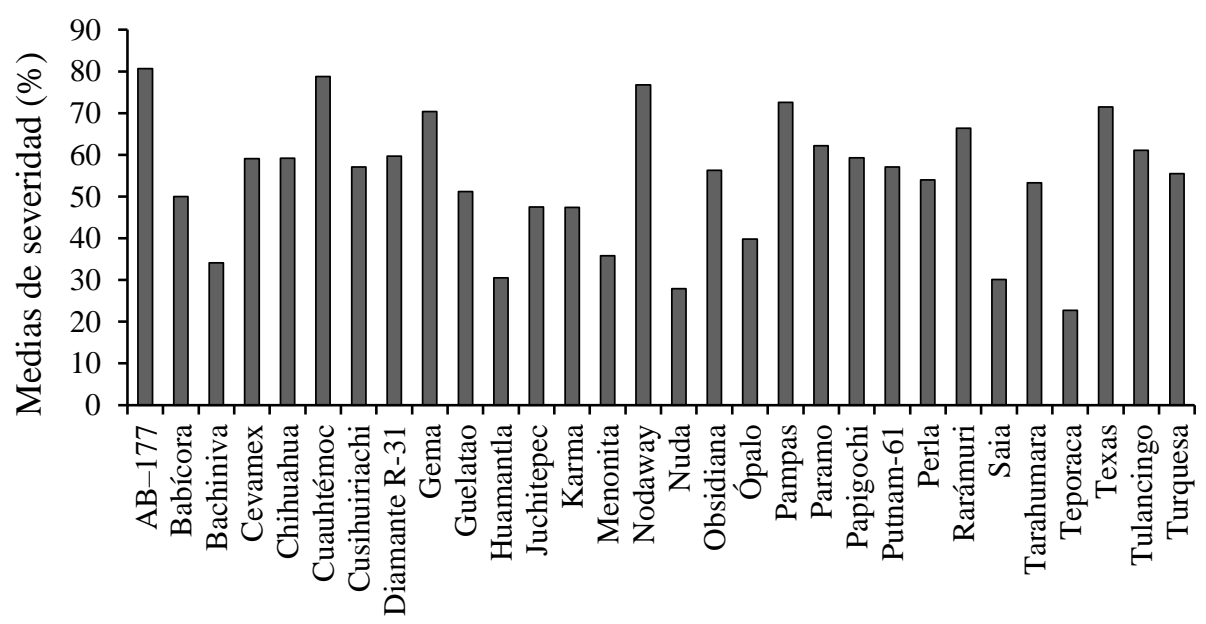

Figura 2. Respuesta grafica de la severidad (\%) causada por $B$. sorokiniana en 30 variedades de avena.

En el estudio se observó que las variedades Cuauhtémoc y Chihuahua fueron moderadamente susceptibles a $B$. victoriae y susceptibles a $B$. sorokiniana. Esto se confirma con los resultados realizados por García-León et al. (2013), quienes reportan alta incidencia de ambas especies fúngicas en campos de avena cultivados con estas variedades en el Estado de México, Tlaxcala e Hidalgo.

Asimismo, Leyva-Mir et al. (2013), al realizar muestreos a partir de semilla aislaron frecuentemente a $B$. sorokiniana y $B$. victoriae.

Con respecto a la variedad Ópalo, los datos indicaron que fue resistente a la infección por $B$. victoriae y moderadamente susceptible a $B$. sorokiniana bajo condiciones de invernadero. Villaseñor-Mir et al. (2009), obtuvieron los mismos resultados y reportaron que esta variedad es moderadamente resistente al complejo de patógenos causantes de enfermedades foliares de la avena, entre los que se encuentran algunas especies de Bipolaris. Sin embargo, en condiciones de campo, García-León et al. (2013), registraron incidencias de aislados de B. sorokiniana de hasta $50 \%$ en campos de avena cultivados con la variedad Ópalo en Estado de México y de la Ciudad de México, pero no registraron la presencia de B. victoriae en dichas muestras. Cabe señalar que, 
aunque la variedad Ópalo mostró ser tolerante a tizones foliares en nuestro estudio, esta variedad se ha reportado como altamente susceptible a enfermedades como roya del tallo y roya de la corona (Espitia-Rangel et al., 1999).

En cuanto a la variedad Teporaca, esta se comportó como moderadamente resistente a la infección por B. sorokiniana y como moderadamente susceptible a B. victoriae. Esto es de gran relevancia, debido a que la variedad Teporaca se registró como resistente a la roya del tallo y roya de la corona en avena (Salmerón-Zamora, 2001) y como moderadamente resistente a la mancha foliar por $C$. graminicola (Leyva-Mir et al., 2004). Lo que podría ser una alternativa en las zonas donde se presentan estas enfermedades.

La variedad Cevamex exhibió un 30 y $59 \%$ de severidad de síntomas causados por B. victoriae y $B$. sorokiniana, respectivamente. Esto indicó que es una variedad susceptible a ambas especies de hongos. Esta variedad se consideró como resistente al complejo de enfermedades foliares cuando se liberó a finales de los 90's (Villaseñor-Mir et al., 1998); no obstante, 10 años después de su liberación, dicha variedad se comportó como moderadamente resistente (Villaseñor-Mir et al., 2008).

De acuerdo a García-León et al. (2013), la variedad Cevamex presentó incidencia de B. victoriae hasta de $40 \%$ en campos comerciales de avena del Estado de México durante los ciclos 2009 y 2010. Mientras que, B. sorokiniana se detectó en incidencias hasta de $70 \%$ en campos de avena del Estado de México, y con incidencias hasta de $40 \%$ en campos de avena pertenecientes al área de la Ciudad de México. El aumento de la susceptibilidad de esta variedad a tizones foliares puede deberse a la adaptación y amplia dispersión de aislados de hongos como Bipolaris spp. en las zonas productoras de avena de los Valles Centrales de México.

La variedad Karma, fue moderadamente susceptible a $B$. victoriae y susceptible a $B$. sorokiniana, lo cual difiere con lo indicado por Villaseñor-Mir et al. (2008), quienes reportaron que esta variedad es moderadamente resistente al complejo de enfermedades foliares. No obstante, los resultados obtenidos coinciden con lo reportado por García-León et al. (2013), quienes registraron alta incidencia (hasta 70\%) de B. victoriae en campos cultivados con la variedad Karma en Hidalgo, Tlaxcala y Estado de México y hasta $30 \%$ de incidencia de B. sorokiniana, en campos de avena con esta variedad en el Estado de México.

Por su parte, Leyva-Mir et al. (2004), señalaron que la variedad Karma es susceptible a la infección por Colletotrichum graminicola, que es otro patógeno considerado dentro del complejo de enfermedades foliares de la avena en México. Las pruebas realizadas en invernadero la variedad Turquesa mostró ser moderadamente resistente a $B$. victoriae y susceptible a $B$. sorokiniana, resultados similares los obtuvo Villaseñor-Mir et al. (2009), quienes reportaron a esta variedad como tolerante al complejo de patógenos foliares, incluyendo a la antracnosis, causada por Colletotrichum graminicola.

En este sentido, García-León et al. (2013), detectaron incidencia de B. sorokiniana (50\%) y B. victoriae (90\%), en campos de avena cultivados con la variedad Turquesa en el estado de Tlaxcala. Respecto a la variedad Obsidiana, esta se comportó moderadamente susceptible a la infección por B. victoriae y susceptible a B. sorokiniana. Contrario a lo indicado por Espitia-Rangel et al. (2007); Villaseñor-Mir et al. (2008), quienes mencionaron que esta variedad es resistente al complejo de enfermedades foliares. 
Resultados similares se observaron por Leyva-Mir et al. (2004), quienes determinaron que esta variedad es moderadamente resistente a la mancha foliar causada por $C$. graminicola. Por su parte, García-León et al. (2013) no encontraron la presencia de B. victoriae y B. sorokiniana en campos cultivados con esta variedad en los estados de Tlaxcala e Hidalgo.

Todo lo anterior, indica que la variedad Obsidiana se ha comportado como resistente en condiciones de campo (Espitia-Rangel et al., 2007; Villaseñor-Mir et al., 2008; García-León et al., 2013), pero bajo inoculaciones artificiales ha mostrado susceptibilidad.

Las variedades Menonita y Saia resultaron ser moderadamente resistentes a $B$. victoriae y moderadamente susceptibles a $B$. sorokiniana en este estudio. Sin embargo, Villaseñor-Mir et al. (2008), reportaron a estas variedades moderadamente susceptible al complejo de enfermedades foliares en avena.

La variedad Juchitepec se comportó como resistente a $B$. victoriae y susceptible a $B$. sorokiniana en nuestro estudio. Esta variedad se ha considerado susceptible al complejo de enfermedades foliares (Villaseñor-Mir et al., 2009). Además, de acuerdo a Leyva-Mir et al. (2004), esta variedad es moderadamente resistente a la mancha foliar de la avena causada por C. graminicola.

De manera general, todas las variedades de avena evaluadas en el presente estudio mostraron ser más susceptibles a la infección por $B$. sorokiniana que a $B$. victoriae.

Esto puede explicarse debido a que $B$. victoriae afecta únicamente al cultivo de avena (Ghabrial et al., 2013; Condon et al., 2014). Mientras que, B. sorokiniana es patógeno de la mayoría de los cereales como maíz, trigo y cebada (Leyva-Mir y González-Iñiguez, 2000), los cuales son cultivos presentes comunes en las áreas donde se cultiva avena en los Valles Altos de México. Asimismo, en el caso de $B$. victoriae, no se había estudiado ampliamente éste patógeno como problema potencial en avena, hasta que García-León et al. (2013); Leyva-Mir et al. (2014) lo detectaron en semillas y tejido foliar de avena en la región central del país, por lo que se propuso realizar la presente investigación y evaluar las principales variedades de avena y su respuesta a $B$. victoriae.

Anteriormente B. victoriae como lo identifica y describe García-León et al. (2013) es un patógeno que afectaba únicamente al cultivo de avena debido a la detección de la toxina victorina por parte de éste patógeno, sin embargo, hoy podemos comprobar que B. victoriae causa síntomas de tizón en pastos, como lo podemos corroborar en el primer reporte de Tian and Smith (2018) en Georgia.

Mata-Santoyo et al. (2018) realizó un estudio de evaluación de la resistencia de variedades de trigo harinero y trigo cristalino a la infección del tizón foliar por Bipolaris sorokiniana el cual según evaluaciones en campo e invernadero en trigo puede presentarse en cualquier etapa de desarrollo de la planta, pero los síntomas son más pronunciados después de espigar, bajo un muestreo al azar en campo se comprobó que, $100 \%$ de las muestras que se recolectaron mostraron síntomas, con dicho estudio se demostró que el principal agente causante del tizón foliar del trigo. Lo anterior comprueba que las enfermedades foliares en cereales como el trigo y avena se encuentran presentes e interactúan en el mismo ambiente, y afectan a ambos cultivos con las mismas repercusiones en cuanto a severidad y nivel de daño en rendimiento y calidad de la cosecha. 
Asad et al. (2009), realizaron un estudio para identificar B. sorokiniana en diversas zonas agroecológicas de Pakistán y como resultado obtuvieron 80 aislados donde se confirmó a la especie causando los síntomas de tizón foliar en el cultivo de trigo; es decir, la enfermedad está fuertemente diseminada en todas las zonas productivas de cereales en el mundo, sin embargo, poco se ha estudiado la resistencia de las variedades ante este patógeno que durante muchos años fue considerado como secundario.

Ayana et al. (2018) afirma que B. sorokiniana causa pérdidas en el cultivo de trigo de hasta $70 \%$ en la producción, motivo por el cual realizó un experimento para estimar la resistencia y susceptibilidad en 294 genotipos de trigo, y en el cual concluyó que 10 genotipos mostraron resistencia, 38 se mostraron como moderadamente resistentes, 120 clasificados como intermedios, 111 como moderadamente susceptibles y 15 genotipos susceptibles. El estudio resulta alarmante, debido a que la comunidad científica centrada en el mejoramiento genético de cereales está centrando su estudio a un patógeno que históricamente ha coexistido con el cultivo de gramíneas por mucho tiempo.

Finalmente, es importante indicar que $B$. sorokiniana es un patógeno ampliamente distribuido en todas las regiones donde se cultivan cereales en el mundo y su rango de ambientes en los que sobrevive prácticamente abarca gran parte de los hábitats, como en rastrojos de cosechas anteriores, en hojas y en semillas de especies como trigo, avena, cebada y otras gramíneas (Minotto et al., 2014), es por ello la importancia de realizar estudios que permitan comprobar el daño y el impacto de éste fitopatógeno en las variedades de avena en México, así como determinar posibles fuentes de resistencia para incluirla en los programas de mejoramiento genético de avena.

\section{Conclusiones}

Las inoculaciones artificiales de $B$. sorokiniana y $B$. victoriae realizadas bajo condiciones de invernadero, determinaron que las variedades de avena AB-177, Cuauhtémoc, Gema, Texas, Nodaway y Pampas se comportaron como las más susceptibles a B. sorokiniana, mientras que, las variedades Teporaca y Nuda mostraron ser moderadamente resistentes a éste patógeno. Para el caso de B. victoriae, se observó que las variedades Juchitepec y Ópalo fueron resistentes, entretanto, las variedades Gema, Bachiniva y Cevamex se comportaron como las más susceptibles a la infección.

Las variedades que presentaron mayor resistencia a la infección por B. sorokiniana y B. victoriae podrían considerarse como fuente de resistencia para el programa de mejoramiento genético de avena en México.

\section{Literatura citada}

Asad, S.; Iftikhar, S. S.; Munir, A. and Ahmad, I. 2009. Characterization of Bipolaris sorokiniana isolated from different agro-ecological zonez of wheat production in Pakistan. Pak. J. Bot. 41(1):301-308.

Ayana, G. T.; Ali, S.; Sidhu, J. S.; González, H. J. L.; Turnipseed, B. and Sehgal, S. K. 2018. Genome-wide association study for spot blotch resistance in hard winter wheat. Front. Plant. Sci. https://doi.org/10.3389/fpls.2018.00926. 
Condon, B. J.; Wu, D.; Krasevec, N.; Horwitz, B. A. and Turgeon, G. 2014. Comparative genomics of Cochliobolus Phytopathogens. In: Genomic of plant-associated fungi. Monocot Pathogens. 41-67 pp.

Consejo Internacional de Cereales. 2018. Mercado de cereales. https://www.igc.int/downloads/ gmrsummary/gmrsumms.pdf.

Espitia-Rangel, E.; Tovar-Gómez, M. R. y Villaseñor-Mir, H. E. 1999. Variedades de avena granoforraje para siembras de temporal en México. Instituto Nacional de Investigaciones Forestales, Agrícolas y Pecuarias (INIFAP). Desplegable técnico núm. 9.8 p.

Espitia-Rangel, E.; Villaseñor-Mir, H. E.; Huerta-Espino, J.; Salmerón-Zamora, J. J.; GonzálezIñiguez, R. M. y Osorio-Alcalá, L. 2007. Obsidiana, variedad de avena para la producción de grano y forraje en México. Agric. Téc. Méx. 33(1):95-98.

FAO. 2014. Organización de las Naciones Unidas para la Alimentación y la Agricultura. http://www.fao.org/worldfoodsituation/csdb/es/.

García-León, E.; Leyva-Mir, S. G.; Villaseñor-Mir, H. E.; Rodríguez-García, M. F. y Tovar-Pedraza, J. M. 2013. Identificación e incidencia de tres hongos fitopatógenos de reporte nuevo en avena (Avena sativa L.), en la meseta central de México. Agrociencia. 47(8):815-827.

García-León, E.; Leyva-Mir, S. G.; Villaseñor-Mir, H. E.; Rodríguez-García, M. F. y TovarPedraza, J. M. 2015. Diversidad e incidencia de hongos asociados a enfermedades foliares de la avena (Avena sativa L.) en los valles altos de México. Rev. Inv. Agrop. 41(1):53-56.

Ghabrial, S. A.; Dunn, S. E.; Li, H.; Xie, J. and Baker, T. 2013. Viruses of Helminthosporium (Cochlioblus) victoriae. In: advances in virus research. Said, A. and Ghabrial, P. (Ed.). Burlington. Academic Press. 289-325 pp.

Leyva-Mir, S. G. y González-Iñiguez, R. M. 2000. Descripción y control de tizones, manchas foliares y roña de la espiga de trigo. In: el trigo de temporal en México. Villaseñor M. H. E. y Espitia R. E. (Eds.). Chapingo, Estado de México, México. SAGAR, INIFAP. Campo Experimental Valle de México. Libro técnico núm. 1. 253-288 pp.

Leyva-Mir, S. G.; Soto-Herrera, A.; Espitia-Rangel, E.; Villaseñor-Mir, H. E.; González-Iñiguez, R. M. y Huerta-Espino, J. 2004. Etiología e incidencia de la antracnosis [Colletotrichum graminicola (Ces.) G. W. Wils.] de la avena (Avena sativa L.) en Michoacán, México. Rev. Mex. Fitopatol. 22(3):351-355.

Leyva-Mir, S. G.; Sillas-Covarrubias, R.; Villaseñor-Mir, H. E.; Mariscal-Amaro, L. A. y Rodríguez-García M. F. 2013. Enfermedades fungosas asociadas al cultivo de avena (Avena sativa L.) en el Estado de México. Rev. Mex. Cienc. Agríc. 4(7): 1103-1107.

Leyva-Mir, S. G.; Cervantes-García, M. A.; Villaseñor-Mir, H. E.; Rodríguez-García, M. F. y Tovar-Pedraza, J. M. 2014. Diversidad de hongos en semilla de avena del valle central de México. Rev. Mex. Cienc. Agríc. 8(1):1379-1385.

Mata-Santoyo, C. I.; Leyva-Mir, S. G.; Camacho-Tapia, M.; Tovar-Pedraza, J. M.; Huerta-Espino, J.; Villaseñor-Mir, H. E. y García-León, E. 2018. Aggressiveness of bipolaris sorokiniana and alternaria alternata isolates on wheat cultivars in Mexico. Rev. Mex. Fitopatol. 36(3):432-443.

Mehta, Y. R. 20 14. Disease appraisal scales. In: Mehta, Y. R. (Ed.). Wheat diseases and their management. Chapter 9. Springer International Publishing Switzerland. 249-252 pp.

Minotto, E.; Bertoni, M. M.; Vélez-Martin, E.; Feltrin, T.; Pasqualini, M. L.; Spadari, C. and Teresinha, S. V. D. S. 2014. Pathogenicity of monosporic and polysporic Bipolaris sorokiniana isolates to wheat seed and seedling under controlled conditions. Afr. J. Microbiol. Res. 28(8):2697-2704. 
Salmerón-Zamora, J. J. 2001. Teporaca: nueva variedad de avena para temporal, resistente a royas y grano de alto peso específico. Agric. Téc. Méx. 27(2):175-176.

SIAP. 2016. Servicio de Información Agrícola y Pecuaria. http://www.siap.sagarpa.gob.mx

Tian, P. and Smith, S. M. 2018. First report of leaf spot caused by Bipolaris victoriae on switchgrass in Georgia. Plant Dis. 102 (3). https://doi.org/10.1094/PDIS-07-17-1010-PDN.

USDA. 2017. United States Department of Agriculture. Foreign Agricultural Service. Office of Global Analysis. 16 p. https://apps.fas.usda.gov/psdonline/circulars/production.pdf.

Villaseñor-Mir, H. E.; Espitia-Rangel, E. y Márquez-Gutiérrez, C. 1998. CEVAMEX, nueva variedad de avena para la producción de grano y forraje en México. Instituto Nacional de Investigaciones Forestales, Agrícolas y Pecuarias (INIFAP). Folleto técnico núm. 12.14 p.

Villaseñor-Mir, H. E.; Espitia-Rangel, E. y Huerta-Espino, J. 2003. El Campo Experimental Valle de México, estratégico en la producción nacional de avena: historia y aportaciones. In: 60 años de investigación en el Campo Experimental Valle de México. (INIFAP)-Centro de Investigación del Centro-Campo Experimental Valle de México. Chapingo, Estado de México, México. Publicación especial núm.1. 17-30 pp.

Villaseñor-Mir, H. E.; Limón-Ortega, A.; Huerta-Espino, J.; Rodríguez-García, M. F.; EspitiaRangel, E. y Leyva-Mir, S. G. 2008. El cultivo de avena en el Estado de México: ambientes de producción, enfermedades, variedades. Instituto Nacional de Investigaciones Forestales, Agrícolas y Pecuarias. Folleto técnico núm. 29. 12 p.

Villaseñor-Mir, H. E.; Espitia-Rangel, E.; Huerta-Espino, J.; Osorio-Alcalá, L. y López Hernández, J. 2009. Turquesa, nueva variedad de avena para la producción de grano y forraje en México. Agric. Téc. Méx. 35(4):480-485. 